\title{
Medidas de combate ao plágio, adotadas por instituições de ensino superior: uma análise da efetividade das ações na área de Ensino.
}

João Paulo Aires joao@utfpr.edu.br 0000-0002-4367-9901 Universidade Tecnológica Federal do Paraná. Ponta Grossa, Paraná, Brasil.

Luiz Alberto Pilatti lapilatti@utfpr.edu.br 0000-0003-2679-9191

Universidade Tecnológica Federal do Paraná. Ponta Grossa, Paraná Brasil.

\section{RESUMO}

O presente estudo teve como objetivo verificar se as Instituições de Ensino Superior (IES) que possuem ações de combate ao plágio registram menores índices de problemas nas dissertações e teses. Trata-se de um estudo documental, realizado em programas de pósgraduação (Mestrado Acadêmico, Mestrado Profissional e Doutorado) da área de Ensino. Para a composição do corpus documental, foram selecionadas 330 dissertações e teses defendidas no período de 2010 a 2012, em 45 instituições. Para a coleta dos dados, foi utilizado o buscador Google. Foram analisados 50 trechos de cada documento (retirados das seções: introdução - 5; referencial teórico - 30; metodologia - 5; resultados e discussão - 10). Os dados foram analisados por meio da estatística descritiva. Analisando de forma isolada as medidas implementadas, tem-se que as ações regulamentares (políticas e regulamentos) e ações preventivas (orientação à comunidade), apesar de terem apresentado menores índices de trechos com plágio, mostraram-se pouco efetivas. Conclui-se que, as medidas de combate ao plágio, promovidas pelas IES, são ineficazes, pois foram encontrados muitos trechos com problemas, inclusive naquelas IES nas quais algumas ações estão formalizadas, sendo necessário intensificá-las e/ou aprimorá-las para o enfrentamento e eliminação desta prática.

PALAVRAS-CHAVE: Plágio. Pós-Graduação. Ensino. Medidas Institucionais. 


\section{INTRODUÇÃO}

A maioria das pesquisas realizadas no mundo, divulgadas por meio de canais formais, são estruturadas de forma adequada e honesta. Entretanto, alguns pesquisadores adulteram os dados, produzindo resultados que podem ter conclusões incorretas, inadequadas e fraudulentas (BERLINCK, 2011; CHIARINI; VIEIRA, 2012; ELLIOTT; MARQUIS; NEAL, 2013; GOMES, 2014). Para que o conhecimento possa ser disseminado de forma íntegra e eficaz, preservando as instituições, é imprescindível que os pesquisadores tenham uma conduta dentro de padrões morais e éticos adequados (CHIARINI, VIEIRA, 2012).

Entretanto, periodicamente, a comunidade depara-se com a divulgação de casos na mídia, seja impressa ou digital, relacionados com a má conduta científica (YOUMANS, 2011; ELLIOTT, MARQUIS, NEAL, 2013; HOFMAN, MYHR, HOLM, 2013; STABINGIS, ŠARLAUSKIENĖ, ČEPAITIENĖ, 2014; WATANABE, 2014). Entre as formas de desonestidade, destacam-se: o plágio e o autoplágio, a falsificação e a fabricação de dados, a não publicação de dados, os erros nos procedimentos de coleta de dados, os erros na retenção e no armazenamento, os problemas de autoria e as práticas duvidosas de publicação (THOMAS, NELSON, SILVERMAN, 2012).

Silva (2008), Vasconcelos et al. (2009), Anderson e Steneck (2011), Coury (2012), Holt (2012) e Martin (2013) argumentam que o plágio (cópia de ideias, dados ou palavras) e o autoplágio (cópia de ideias do próprio autor) são inaceitáveis para a comunidade e devem ser eliminados, pois se tratam da cópia de algo sem dar o devido crédito ao proprietário, independentemente da quantidade utilizada (SILVA, 2008; VASCONCELOS et al., 2009; ANDERSON; STENECK, 2011; COURY, 2012; HOLT, 2012; MARTIN, 2013).

Cabe à universidade gerar conhecimento e informação que possam ser úteis para a sociedade, sendo imprescindível estruturar documentos internos (políticas, regulamentos, normativos) com base nos princípios da ética e da conduta de pesquisa responsável, além de desenvolver ações de orientação por meio de seminários, palestras e oficinas acerca de plágio (VASCONCELOS et al., 2009; MARSHALL et al., 2011; JORDAN; GRAY, 2012; ELLIOTT; MARQUIS; NEAL, 2013; GOMES, 2014).

Em 2011, a Coordenação de Aperfeiçoamento de Pessoal de Nível Superior (CAPES) enviou um documento contendo recomendações às instituições de ensino superior (IES), públicas e privadas, referente à adoção de ações de enfrentamento ao plágio acadêmico em artigos, monografias, dissertações ou teses (BERLINCK, 2011; CAPES, 2011; HOLT, 2012, ELLIOT; MARQUIS; NEAL, 2013). Para a CAPES, cabe às IES brasileiras o desenvolvimento de políticas para orientação, detecção e punição para os casos em que se constate plágio.

A orientação da CAPES foi originada por demanda apresentada pela Ordem dos Advogados do Brasil (OAB) do Ceará, que aprovou um relatório sobre o plágio nas instituições de ensino (OAB, 2010). O relatório enfatiza que "[...] muitos 
falha grave em relação aos direitos autorais, fragilizando as instituições de ensino superior, além de enfraquecer a pesquisa.

Com as facilidades no acesso à informação, o meio acadêmico é o ambiente que mais tem apresentado casos de obtenção de proveitos que são incompatíveis com sua capacidade, provenientes do acesso à internet e da cópia de material produzido por outra pessoa (PREVEDELLO; ROSSI; COSTA, 2015; WACHOWICZ, 2015; WACHOWICZ; COSTA, 2016). Porém, da mesma forma que a internet permite aos alunos copiarem qualquer informação (texto ou imagem) de forma rápida, também permite que a fonte copiada seja descoberta (SAUTHIER et al., 2011, p. 52).

Conforme abordado nos trabalhos de Marshall et al (2011) e DeGeeter et al. (2014), para combater o plágio no meio acadêmico é necessário que sejam desenvolvidas ações, normas e regulamentos, treinamentos e seminários, dos quais a comunidade possa participar para compreender a gravidade do problema e fortalecer a escrita científica. Adicionalmente, as instituições podem adotar softwares como apoio à detecção de plágio e, assim, identificar os trechos em que foram encontrados problemas (MARTIN, 2013).

No Brasil, em julho de 1998, foi sancionada a Lei 9.610, denominada Lei de Direitos Autorais e Conexos. Esta legislação é, ao contrário de leis similares em outros países, na ótica de Wachowicz e Costa (2016, p. 20), "[...] uma das mais rígidas e restritivas do mundo", pois não é permitida a reprodução, fotocópia ou digitalização de acervo, sendo considerada uma contrafação (reprodução não autorizada). A Lei 9.610/1998 protege as obras originais, criadas por meio da capacidade criativa do ser humano, sendo divulgadas por qualquer meio utilizado (BRASIL, 1998). Entretanto, Moraes (2014) e Wachowicz e Costa (2016) destacam que a Lei 9.610/1998 precisa de atualização quanto ao uso da internet, pois, na época de sua promulgação, o acesso aos meios digitais não eram tão facilitados como atualmente.

A legislação de Direito Autoral brasileira não concede proteção à ideia, mas à expressão da mesma, ou seja, é necessário ter algo materializado, publicado e disponível em algum lugar, para que seja passível de proteção e de amparo legal (BRASIL, 1998; PREVEDELLO; ROSSI; COSTA, 2015). (PREVEDELLO; ROSSI; COSTA, 2015; WACHOWICZ; COSTA, 2016). Entretanto, algumas ações não constituem violação como a citação de trechos de obras, acompanhadas do nome do autor e a origem (ESTEVES, 2014; PREVEDELLO; ROSSI; COSTA, 2015).

Estudos apontam que o plágio é um dos principais problemas relacionados à desonestidade acadêmica e uma das formas que mais prejudica e desgasta o cenário científico (FANELLI, 2009; MARTIN, 2013; LIU, LO, WANG, 2013). A discussão desta temática no Brasil é, ainda, frágil e incipiente (ALENCAR, 2016; DALLA COSTA, 2016; SOUZA et al., 2016) e não há unanimidade quanto à disponibilização de regulamentos, normas e diretrizes (KROKOSCZ, 2011). Almeida et al. (2016) destacam que os países com menor tradição acadêmica (e, consequentemente, menor fator de impacto em pesquisa e volume de citações), têm regras menos rígidas para combater os casos de plágio. Consequentemente, nestes países, os procedimentos para garantir a integridade acadêmica são menos presentes e difundidos. Com efeito, a ocorrência de situações desta natureza é muito maior. 
Destaca-se, também, que apenas a disciplina de Metodologia de Pesquisa, no ambiente universitário, é insuficiente para abordar todos os assuntos e problemas causados pela desonestidade científica. Assim, é importante a institucionalização de regulamentos, definir punições no caso de violação de direito autoral, bem como orientar periodicamente a comunidade universitária sobre as diretrizes para elaboração dos trabalhos (ANDRADE, 2011; INNARELLI, 2011; TANIGUCHI, 2011; KROKOSCZ, 2014; VELUDO-DE-OLIVEIRA et al., 2014; SANTOS, 2015; ALENCAR, 2016; ALVES, MOURA, 2016).

A presente pesquisa teve por objetivo verificar se as Instituições de Ensino Superior (IES) que possuem ações de combate ao plágio apresentam menores índices de plágio nas dissertações e teses na área de Ensino. Optou-se, então, em selecionar produções desta área, uma vez que os programas ofertados, geralmente possuem no quadro discente um número significativo de professores matriculados. Assim, se por ventura um professor não aplicar/obedecer adequadamente às regras metodológicas/institucionais, muito provavelmente terá dificuldades em orientar seus alunos nesta tarefa.

\section{METODOLOGIA}

Através deste trabalho foi realizado um levantamento, sendo que o corpus documental da pesquisa é composto por dissertações e teses defendidas nos programas de Pós-Graduação na área de Ensino, no período de 2010 a 2012.

Para efetuar as análises das produções, foram utilizados todos os programas de Pós-Graduação (Mestrado Acadêmico, Mestrado Profissional e Doutorado) na área do Ensino, recomendados pela CAPES. Os documentos selecionados para análise foram identificados nos Cadernos de Indicadores de teses e dissertações de cada IES (pública ou privada). Para o cálculo da amostra, foi utilizada equação para estimar o número mínimo de documentos a serem analisados, considerando uma população finita (Equação 1).

$$
n=\frac{N \cdot Z^{2} \cdot p \cdot(1-p)}{(N-1)-e^{2}+Z^{2} \cdot p \cdot(1-p)}
$$

Equação 1 - Cálculo para pequenas amostras

Onde:

$n=$ tamanho da amostra

$N=$ tamanho da população

$Z$ = desvio padrão para o valor médio. Se o nível de confiança desejado é 95\%, adota-se para $Z$ o valor de 1,96. Se o nível de confiança for $99 \%$, adota-se para $Z$ o valor de 2,575

$e=$ é a margem de erro máxima ( $5 \%$ ou $1 \%$ )

$p=$ é a proporção desejada. Como não se conhece este valor por padrão, adotase o valor 50 (equivalente a $50 \%$ ) 
Para efetuar o cálculo da amostra, foi adotado um desvio padrão com $95 \%$ de confiança e uma margem de erro de 5\%, resultando na seleção de 330 documentos.

Conforme cálculo, a amostra mínima para o desenvolvimento deste estudo foi de 330 documentos, que foram distribuídos de forma estratificada, com base no volume produzido em cada programa, sendo: 154 retirados de programas de Mestrado, 140 de Mestrado Profissional e 36 de Doutorado.

Para cada documento analisado, foram utilizados 50 trechos (frases com seis palavras em sequência) selecionados aleatoriamente e retirados das seções: Introdução (5 trechos); Revisão de Literatura (30 trechos): Metodologia (5 trechos); e, Discussões (10 trechos), totalizando 16.500 trechos avaliados. Para compor a análise, foram consideradas apenas as sentenças com citações indiretas, sendo, preferencialmente, com trechos que mantivessem o anonimato da fonte.

A análise da ocorrência de plágio nas sentenças selecionadas foi realizada por meio da comparação textual, usando a ferramenta de busca Google, uma vez que esta realiza a consulta em diversos documentos disponíveis (sítios na internet, livros, artigos de periódicos e de congressos, legislações, entre outros). Nenhum software de deteç̧ão de plágio foi utilizado para efetuar a análise, uma vez que foram utilizados trechos aleatórios de locais pré-determinados, e, apesar de mais trabalhosa, a análise manual produz resultados mais confiáveis.

Cada trecho analisado foi colocado entre aspas, de modo que apenas o texto exato fosse considerado na pesquisa e, assim, confrontado com algum trecho disponível em outra fonte. Para se confirmar a existência de similaridade entre trechos, a data em que o suposto documento semelhante, encontrado na busca pelo Google, foi publicado, deveria ser anterior ao trecho do documento submetido à análise.

No caso de existir semelhança, o trecho foi identificado como plágio e classificado nas categorias "Parcialmente coincidente" (trecho parecido) ou "Coincidente" (trecho igual), caso contrário, descarta-se o trecho e classifica-o como "Não coincidente". Em cada trecho cuja semelhança com documentos externos foi comprovada, foram registrados os dados da fonte utilizada (autor, tipo da fonte, ano de produção, local disponível). Para o registro de cada documento analisado, utilizou-se totalização de trechos plagiados, os quais foram classificados em níveis de coincidência textual, sendo atribuídos os seguintes pesos: coincidência textual mínima (abaixo de $5 \%$ de trechos plagiados); baixa coincidência textual (entre $5 \%$ e $10 \%$ de trechos com plágio); coincidência textual moderada (entre $10 \%$ e $20 \%$ de trechos com problema); coincidência textual elevada (acima de $20 \%$ ).

Adicionalmente, por meio de consulta à página de cada IES, foram verificadas/registradas as políticas disponíveis (legislação, instruções normativas, regulamentos, manuais de escrita científica) e ações desenvolvidas periodicamente em cada instituição, de modo a efetuar a comparação acerca das políticas adotadas com a proporção de plágio produzido nos trechos analisados, de modo a conferir a eficiência das ações registradas pelas instituições.

O tratamento adotado pelas instituições em relação ao plágio divide-se em: ações sistematizadas de combate ao problema (palestras, oficinas, seminários) 
por meio da formalização de instrumentos de controle e políticas institucionalizadas, tais como regulamentos, instruções normativas, regimentos internos. A obtenção dos dados foi realizada por meio de consulta às páginas oficiais das IES, utilizando as palavras "plágio" e "desonestidade em pesquisa".

Para avaliar a proporção de plágio registrada, as IES foram distribuídas segundo a quantidade de ações que desenvolvem. Após categorizar cada IES e, posteriormente, contabilizar a quantidade de trechos com plágio, a proporção de plágio foi calculada com base na quantidade de ações e nos percentuais de textos com plágio e nível de plágio. Para preservar as IES, criou-se uma codificação de 1 a 45 (IES 1, IES 2, ... IES 45), sendo aplicada após a classificação em dois níveis e em ordem alfabética crescente: a) região (nível 1); b) nome da IES (nível 2).

Considerando a revisão de literatura acerca de integridade em pesquisa, levantou-se a seguinte hipótese básica (HB):

- Quanto maior a quantidade de ações de combate ao plágio desenvolvidas nas instituições de ensino superior (IES), menor será a quantidade de plágio nos documentos elaborados pelos estudantes.

Decorrentes da hipótese básica foram levantadas as seguintes hipóteses secundárias (HS):

- HS1 - Quanto mais ações regulamentares desenvolvidas na IES, menor o volume de documentos/trechos com plágio;

- HS2 - Quanto mais ações preventivas realizadas na IES, menor o volume de documentos/trechos com plágio;

- HS3 - Toda IES que adota medidas diagnósticas para validar os documentos, não apresenta plágio nos trabalhos produzidos pelos estudantes;

- HS4 - Quanto maior a quantidade de medidas corretivas utilizadas na IES, menor a probabilidade de apresentar documentos/trechos com plágio;

No Quadro 1 são registradas as hipóteses, básica e secundárias, associadas às variáveis independente e dependente.

Quadro 1 - Variáveis e hipóteses de pesquisa

\begin{tabular}{|l|c|c|}
\hline Hipóteses & \multicolumn{1}{|c|}{$\begin{array}{c}\text { Variável } \\
\text { Independente }\end{array}$} & $\begin{array}{c}\text { Variável } \\
\text { Dependente }\end{array}$ \\
\hline $\begin{array}{l}\text { HB - Quanto maior a quantidade de } \\
\text { ações de combate ao plágio } \\
\text { desenvolvidas nas instituições de } \\
\text { ensino superior (IES), menor será a } \\
\text { quantidade de plágio nos documentos } \\
\text { elaborados pelos estudantes. }\end{array}$ & Ações de combate & Quantidade de plágio \\
\hline $\begin{array}{l}\text { HS1 Quanto mais ações } \\
\text { regulamentares desenvolvidas na IES, } \\
\text { menor o volume de } \\
\text { documentos/trechos com plágio. }\end{array}$ & Ações regulamentares & $\begin{array}{c}\text { Documentos/ } \\
\text { trechos }\end{array}$ \\
\hline HS2 - Quanto mais ações preventivas & Ações preventivas & Documentos/ \\
\hline
\end{tabular}




\begin{tabular}{|l|l|l|}
\hline $\begin{array}{l}\text { realizadas na IES, menor o volume de } \\
\text { documentos/trechos com plágio. }\end{array}$ & Trechos \\
\hline $\begin{array}{l}\text { HS3 - Toda IES que adota medidas } \\
\text { diagnósticas para validar os } \\
\text { documentos, não apresenta plágio } \\
\text { nos trabalhos produzidos pelos } \\
\text { estudantes. }\end{array}$ & Medidas diagnósticas & Plágio \\
\hline $\begin{array}{l}\text { HS4 - Quanto maior a quantidade de } \\
\text { medidas corretivas utilizadas na IES, } \\
\text { menor a probabilidade de apresentar } \\
\text { documentos/trechos com plágio. }\end{array}$ & Medidas corretivas & $\begin{array}{c}\text { Documentos/ } \\
\text { Trechos }\end{array}$ \\
\hline \begin{tabular}{l} 
Fonte: Autoria própria (2017). \\
\hline
\end{tabular}
\end{tabular}

\section{RESULTADOS}

Para melhor estruturar os dados obtidos junto às IES, foi adotada a organização em categorias disponível em Krokoscz (2011), sendo:

- Ações regulamentares: 1. Página contendo informações acerca de plágio; 2. Política institucional sobre o plágio; 3. Cartilhas, manuais e/ou documentos oficiais sobre o assunto; 4. Comissão de Integridade Científica ou Processo Administrativo Disciplinar.

- Ações preventivas: 1. Ações de orientação da comunidade (palestras, seminários, formulários de declaração de autoria); 2. Capacitação da comunidade (cursos de qualificação, exercícios de escrita científica, regras gerais para a elaboração de trabalhos de conclusão de curso).

- Medidas diagnósticas: 1. Ferramenta para detecção de plágio.

- Medidas corretivas: 1. Descrição do plágio em regulamentos internos (Direitos e deveres do estudante); 2. Medidas punitivas (advertência, suspensão, expulsão).

O Quadro 2 apresenta, de forma geral, o registro das ações e/ou medidas desenvolvidas em cada IES. Foram identificadas no quadro, as nove ações divididas nas categorias pesquisadas (ações regulamentares, ações preventivas, medidas diagnósticas e corretivas). 
Quadro 2 - Ações e medidas desenvolvidas nas IES

\begin{tabular}{|c|c|c|c|c|c|c|c|c|c|}
\hline \multirow[t]{2}{*}{ Instituição } & \multicolumn{4}{|c|}{$\begin{array}{c}\text { Ações } \\
\text { regulamentares }\end{array}$} & \multicolumn{2}{|c|}{$\begin{array}{c}\text { Ações } \\
\text { preventivas }\end{array}$} & \multirow{2}{*}{$\begin{array}{c}\text { Medidas } \\
\text { diagnósticas }\end{array}$} & \multicolumn{2}{|c|}{$\begin{array}{l}\text { Medidas } \\
\text { corretivas }\end{array}$} \\
\hline & 1 & 2 & 3 & 4 & 1 & 2 & & 1 & 2 \\
\hline IES 1 & $\checkmark$ & & $\checkmark$ & $\checkmark$ & $\checkmark$ & & & & $\checkmark$ \\
\hline IES 2 & & $\checkmark$ & $\checkmark$ & & & & & $\checkmark$ & $\checkmark$ \\
\hline IES 3 & $\checkmark$ & & & & & & & & $\checkmark$ \\
\hline IES 4 & & & & & $\checkmark$ & & & & \\
\hline IES 5 & & & & & & & & $\checkmark$ & $\checkmark$ \\
\hline IES 6 & $\checkmark$ & & & & & & & & \\
\hline IES 7 & & & $\checkmark$ & & & & & $\checkmark$ & \\
\hline IES 8 & $\checkmark$ & & & & $\checkmark$ & & & & \\
\hline IES 9 & & $\checkmark$ & $\checkmark$ & & $\checkmark$ & & $\checkmark$ & $\checkmark$ & $\checkmark$ \\
\hline IES 10 & $\checkmark$ & & $\checkmark$ & & $\checkmark$ & & & & \\
\hline IES 11 & & $\checkmark$ & & & $\checkmark$ & & & $\checkmark$ & $\checkmark$ \\
\hline IES 12 & & & $\checkmark$ & & $\checkmark$ & & & & \\
\hline IES 13 & & & $\checkmark$ & & $\checkmark$ & & & & \\
\hline IES 14 & $\checkmark$ & & & & & & & & \\
\hline IES 15 & $\checkmark$ & & $\checkmark$ & & $\checkmark$ & & & & \\
\hline IES 16 & & & $\checkmark$ & & & & & $\checkmark$ & $\checkmark$ \\
\hline \multicolumn{10}{|l|}{ IES 17} \\
\hline IES 18 & $\checkmark$ & $\checkmark$ & & & & & $\checkmark$ & $\checkmark$ & $\checkmark$ \\
\hline IES 19 & $\checkmark$ & & & $\checkmark$ & $\checkmark$ & & & & \\
\hline IES 20 & $\checkmark$ & & $\checkmark$ & & $\checkmark$ & $\checkmark$ & & & \\
\hline IES 21 & & & & & $\checkmark$ & & & $\checkmark$ & $\checkmark$ \\
\hline IES 22 & $\checkmark$ & & & & & & & & \\
\hline IES 23 & & & & $\checkmark$ & & & & & \\
\hline IES 24 & & & & & & & $\checkmark$ & & \\
\hline \multicolumn{10}{|l|}{ IES 25} \\
\hline IES 26 & & & & & & & $\checkmark$ & & $\checkmark$ \\
\hline \multicolumn{10}{|l|}{ IES 27} \\
\hline IES 28 & & & & & & & $\checkmark$ & & \\
\hline \multicolumn{10}{|l|}{ IES 29} \\
\hline IES 30 & & & & & & & & $\checkmark$ & \\
\hline IES 31 & $\checkmark$ & & & & & & & & \\
\hline IES 32 & & & & & & $\checkmark$ & $\checkmark$ & $\checkmark$ & $\checkmark$ \\
\hline \multicolumn{10}{|l|}{ IES 33} \\
\hline IES 34 & $\checkmark$ & & & & & & & & \\
\hline \multicolumn{10}{|l|}{ IES 35} \\
\hline IES 36 & & & $\checkmark$ & & $\checkmark$ & & & $\checkmark$ & $\checkmark$ \\
\hline \multicolumn{10}{|l|}{ IES 37} \\
\hline IES 38 & & & & & $\checkmark$ & $\checkmark$ & & $\checkmark$ & $\checkmark$ \\
\hline IES 39 & $\checkmark$ & & & & & & $\checkmark$ & $\checkmark$ & $\checkmark$ \\
\hline IES 40 & $\checkmark$ & $\checkmark$ & & & & & & $\checkmark$ & $\checkmark$ \\
\hline \multicolumn{10}{|l|}{ IES 41} \\
\hline \multicolumn{10}{|l|}{ IES 42} \\
\hline IES 43 & & & & & $\checkmark$ & & $\checkmark$ & $\checkmark$ & \\
\hline \multicolumn{10}{|l|}{ IES 44} \\
\hline IES 45 & $\checkmark$ & $\checkmark$ & 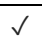 & & $\checkmark$ & & & & \\
\hline
\end{tabular}

Fonte: Autoria própria (2017).

O Quadro 3 apresenta a quantidade de ações e as IES que possuem o volume de medidas identificado. Conforme apresentado, 10 (22,2\%) IES não desenvolvem nenhuma ação; 10 (22,2\%) IES possuem apenas 1 ação formalizada; 7 IES (15,6\%) implementam duas ações; 6 (13,3\%) IES realizam três ações periodicamente; $9(20,0 \%)$ IES tem formalizadas quatro ações; e, 3 (6,7\%) IES implementam cinco ações ou mais. 
Quadro 3 - Políticas desenvolvidas e ações adotadas nas IES

\begin{tabular}{|c|c|}
\hline Quantidade de Ações & Instituições \\
\hline Nenhuma ação & $\begin{array}{l}10 \text { IES - 22,2\% } \\
\text { (IES 17, IES 25, IES 27, IES 29, IES 33, IES 35, IES 37, IES 41, IES 42, IES } \\
44)\end{array}$ \\
\hline Uma ação & $\begin{array}{l}10 \text { IES - 22,2\% } \\
(\text { IES 4, IES 6, IES 14, IES 22, IES 23, IES 24, IES 28, IES 30, IES 31, IES 34) }\end{array}$ \\
\hline Duas ações & $\begin{array}{l}7 \text { IES - 15,6\% } \\
(\text { IES 3, IES 5, IES 7, IES 8, IES 12, IES 13, IES 26) }\end{array}$ \\
\hline Três ações & $\begin{array}{l}6 \text { IES - 13,3\% } \\
\text { (IES 10, IES 15, IES 16, IES 19, IES 21, IES 43) }\end{array}$ \\
\hline Quatro ações & $\begin{array}{l}9 \text { IES - 20,0\% } \\
\text { (IES 2, IES 11, IES 20, IES 32, IES 36, IES 38, IES 39, IES 40, IES 45) }\end{array}$ \\
\hline Cinco ações ou mais & $\begin{array}{l}3 \text { IES - 6,7\% } \\
(\text { IES 1, IES 9, IES 18) }\end{array}$ \\
\hline
\end{tabular}

Fonte: Autoria própria (2017)

Na Tabela 1, encontram-se registrados: a quantidade de trechos analisados, o total de plágio encontrado e a distribuição dos trechos segundo os níveis de classificação definidos no Quadro 3, totalizados mediante a proporção obtida em cada IES. Tal distribuição foi realizada de modo a estabelecer um comparativo entre o volume de plágio obtido e as ações desenvolvidas nas IES. A porcentagem calculada na coluna 2 foi efetuada com base no total de trechos analisados (considerando o total de documentos), enquanto que a porcentagem da coluna 3, baseou-se no total de trechos analisados por IES/ação. 
Tabela 1 - Proporção de plágio versus políticas e medidas desenvolvidas

\begin{tabular}{|c|c|c|c|c|c|c|}
\hline \multirow{2}{*}{ Categoria } & \multirow{2}{*}{$\begin{array}{c}\text { Trechos } \\
\text { Analisados }\end{array}$} & \multirow{2}{*}{$\begin{array}{c}\text { Total de } \\
\text { plágio }\end{array}$} & \multicolumn{4}{|c|}{ NÍVEL DE PLÁGIO } \\
\hline & & & 1 & 2 & 3 & 4 \\
\hline Nenhuma ação & $\begin{array}{c}3.550 \\
(21,5 \%)\end{array}$ & $\begin{array}{c}507 \\
(14,3 \%)\end{array}$ & $\begin{array}{c}9 \\
(1,8 \%)\end{array}$ & $\begin{array}{c}81 \\
(16,0 \%)\end{array}$ & $\begin{array}{c}136 \\
(26,8 \%)\end{array}$ & $\begin{array}{c}281 \\
(55,4 \%)\end{array}$ \\
\hline Uma ação & $\begin{array}{c}3.850 \\
(23,3 \%)\end{array}$ & $\begin{array}{c}429 \\
(11,1 \%)\end{array}$ & $12(2,8 \%)$ & $\begin{array}{c}63 \\
(14,7 \%)\end{array}$ & $\begin{array}{c}179 \\
(41,7 \%)\end{array}$ & $\begin{array}{c}175 \\
(40,8 \%)\end{array}$ \\
\hline Duas ações & $\begin{array}{c}1.650 \\
(10,0 \%)\end{array}$ & $\begin{array}{c}201 \\
(12,2 \%)\end{array}$ & $\begin{array}{c}7 \\
(3,4 \%)\end{array}$ & $\begin{array}{c}14 \\
(7,0 \%)\end{array}$ & $\begin{array}{c}121 \\
(60,2 \%)\end{array}$ & $\begin{array}{c}59 \\
(29,4 \%)\end{array}$ \\
\hline Três ações & $\begin{array}{l}1.550 \\
(9,4 \%)\end{array}$ & $\begin{array}{c}138 \\
(8,9 \%)\end{array}$ & $11(7,9 \%)$ & $\begin{array}{c}29 \\
(21,0 \%)\end{array}$ & $\begin{array}{c}47 \\
(34,1 \%)\end{array}$ & $\begin{array}{c}51 \\
(37,0 \%)\end{array}$ \\
\hline Quatro ações & $\begin{array}{c}4.100 \\
(24,8 \%)\end{array}$ & $\begin{array}{c}401 \\
(9,8 \%)\end{array}$ & $20(4,9 \%)$ & $\begin{array}{c}74 \\
(18,5 \%)\end{array}$ & $\begin{array}{c}143 \\
(35,7 \%)\end{array}$ & $\begin{array}{c}164 \\
(40,9 \%)\end{array}$ \\
\hline Cinco ações ou mais & $\begin{array}{c}1.800 \\
(10,9 \%)\end{array}$ & $\begin{array}{c}266 \\
(14,7 \%)\end{array}$ & $\begin{array}{c}7 \\
(2,5 \%)\end{array}$ & $\begin{array}{c}14 \\
(5,3 \%)\end{array}$ & $\begin{array}{c}81 \\
(30,5 \%)\end{array}$ & $\begin{array}{c}164 \\
(61,7 \%)\end{array}$ \\
\hline $\begin{array}{l}\text { Legenda: } \\
1 \text { - Coincidência textu } \\
3 \text { - Coincidência textu }\end{array}$ & $\begin{array}{l}\text { mínima; } 2 \text { - } \\
\text { moderada; }\end{array}$ & - Coincidêr & $\begin{array}{l}\text { idência tex } \\
\text { ncia textua }\end{array}$ & $\begin{array}{l}\text { tual; } \\
\text { l elevada. }\end{array}$ & & \\
\hline
\end{tabular}

Para que se possa comparar a efetividade de cada ação e/ou medida adotada nas IES, o Quadro 2 foi dividido em quatro outros: um quadro compara a quantidade de ações regulamentares desenvolvidas; outro realiza a totalização das ações preventivas identificadas; um terceiro quadro registra a disponibilidade de medidas diagnósticas na IES; e, o último totaliza as medidas corretivas implementadas.

O Quadro 4 apresenta as ações regulamentares promovidas nas IES. Para contabilização dos resultados, foi verificada a implementação das quatro ações, a saber: a) Página da IES contendo informações acerca de plágio e integridade em pesquisa; b) Política institucional que aborde sobre o plágio; c) Disponibilidade de cartilhas, manuais e/ou documentos oficiais sobre o assunto; d) Existência de Comissão de Integridade Científica ou de Processo Disciplinar.

Quadro 4 - Ações regulamentares promovidas nas IES

\begin{tabular}{|l|l|}
\hline \multicolumn{1}{|c|}{ Ações regulamentares } & \multicolumn{1}{|c|}{ Instituições } \\
\hline & 20 IES $-44,5 \%$ \\
& \\
Nenhuma ação & $($ IES 4, IES 5, IES 17, IES 21, IES 24, IES 25, IES 26, IES 27, IES 28, IES \\
& 29, IES 30, IES 32, IES 33, IES 35, IES 37, IES 38, IES 41, IES 42, IES \\
& 43, IES 44) \\
\hline
\end{tabular}




\begin{tabular}{|l|l|}
\hline \multirow{3}{*}{ Uma ação } & $\begin{array}{l}15 \text { IES - 33,3\% } \\
\text { (IES 3, IES 6, IES 7, IES 8, IES 11, IES 12, IES 13, IES 14, IES 16, IES 22, } \\
\text { IES 23, IES 31, IES 34, IES 36, IES 39) }\end{array}$ \\
\hline Duas ações & 8 IES - 17,8\% \\
& (IES 2, IES 9, IES 10, IES 15, IES 18, IES 19, IES 20, IES 40) \\
\hline Três ações & 2 IES - 4,4\% \\
& (IES 1, IES 45) \\
\hline Quatro ações & Nenhuma IES realiza as quatro ações \\
\hline
\end{tabular}

Fonte: Autoria própria (2017)

A Tabela 2 identifica a proporção de plágio produzida nas IES, conforme a quantidade de ações regulamentares realizadas. A maior taxa de trechos (893 $12,8 \%$ dos 1.942 detectados) com plágio foi registrada para as IES que não promovem nenhuma ação. A porcentagem calculada na coluna 2 foi efetuada com base no total de trechos analisados (considerando o total de documentos), enquanto que a porcentagem da coluna 3 se baseou no total de trechos analisados por IES/ação.

\begin{tabular}{|c|c|c|c|c|c|c|}
\hline \multicolumn{6}{|c|}{ Tabela 2 - Ações regulamentares e o volume de plágio produzido } \\
\hline \multirow{2}{*}{$\begin{array}{c}\text { Ações } \\
\text { regulamentares }\end{array}$} & $\begin{array}{c}\text { Trechos } \\
\text { Analisados }\end{array}$ & \multirow{2}{*}{$\begin{array}{c}\text { Total de } \\
\text { plágio }\end{array}$} & \multicolumn{5}{|c|}{ NíVEL DE PLÁGIO } \\
\cline { 5 - 7 } & & 1 & 2 & 3 & 4 \\
\hline Nenhuma ação & 7.000 & 893 & 29 & 134 & 257 & 473 \\
& $(42,6 \%)$ & $(12,8 \%)$ & $(3,2 \%)$ & $(15,0 \%)$ & $(28,8 \%)$ & $(53,0 \%)$ \\
\hline Uma ação & 5.550 & 531 & 23 & 88 & 261 & 159 \\
& $(33,7 \%)$ & $(7,6 \%)$ & $(4,3 \%)$ & $(16,6 \%)$ & $(49,2 \%)$ & $(29,9 \%)$ \\
\hline Duas ações & 3.100 & 417 & 9 & 49 & 138 & 221 \\
& $(18,8 \%)$ & $(6,0 \%)$ & $(2,2 \%)$ & $(11,8 \%)$ & $(33,1 \%)$ & $(53,0 \%)$ \\
\hline Três ações & 800 & 101 & 5 & 4 & 51 & 41 \\
& $(4,9 \%)$ & $(1,4 \%)$ & $(5,0 \%)$ & $(4,0 \%)$ & $(50,5 \%)$ & $(40,6 \%)$ \\
\hline Quatro ações & 0 & 0 & 0 & 0 & 0 & 0 \\
& $(0,0 \%)$ & $(0,0 \%)$ & $(0,0 \%)$ & $(0,0 \%)$ & $(0,0 \%)$ & $(0,0 \%)$ \\
\hline
\end{tabular}

Legenda:

1 - Coincidência textual mínima; 2 - Baixa coincidência textual;

3 - Coincidência textual moderada; 4 - Coincidência textual elevada.

Fonte: Autoria própria (2017)

O Quadro 5 ilustra a quantidade de ações preventivas desenvolvidas e as IES que realizam tais ações. Para elaboração deste quadro, foi analisada a disponibilidade das seguintes ações: a) Orientação da comunidade (palestras, seminários, declaração de autoria); b) Capacitação (cursos de extensão - escrita científica, regras para a elaboração de trabalhos).

Quadro 5 - Ações preventivas promovidas nas IES

\begin{tabular}{|l|l|}
\hline \multicolumn{1}{|c|}{ Ações preventivas } & \multicolumn{1}{c|}{ Instituições } \\
\hline \multirow{2}{*}{ Nenhuma ação } & 28 IES - 62,2\% \\
& (IES 2, IES 3, IES 5, IES 6, IES 7, IES 14, IES 16, IES 17, IES 18, IES 22, \\
\hline
\end{tabular}




\begin{tabular}{|l|l|}
\hline & IES 23, IES 24, IES 25, IES 26, IES 27, IES 28, IES 29, IES 30, IES 31, \\
& IES 33, IES 34, IES 35, IES 37, IES 39, IES 40, IES 41, IES 42, IES 44) \\
\hline \multirow{3}{*}{ Uma ação } & 15 IES - 33,3\% \\
& $\begin{array}{l}\text { (IES 1, IES 4, IES 8, IES 9, IES 10, IES 11, IES 12, IES 13, IES 15, IES } \\
19, \text { IES 21, IES 32, IES 36, IES 43, IES 45) }\end{array}$ \\
\hline \multirow{3}{*}{ Duas ações } & 2 IES - 4,5\% \\
& $($ IES 20, IES 38) \\
\hline
\end{tabular}

Fonte: Autoria própria (2017)

A Tabela 3 identifica a proporção de plágio produzida nas IES, conforme a quantidade de ações preventivas realizadas. A menor incidência de trechos com plágio foi registrada nas IES que promovem duas ações. A porcentagem calculada na coluna 2 foi efetuada com base no total de trechos analisados (considerando o total de documentos), enquanto que a porcentagem da coluna 3 se baseou no total de trechos analisados por IES/ação.

\begin{tabular}{|c|c|c|c|c|c|c|}
\hline \multirow{2}{*}{ Ações preventivas } & \multirow{2}{*}{$\begin{array}{c}\text { Trechos } \\
\text { Analisados }\end{array}$} & \multirow{2}{*}{$\begin{array}{c}\text { Total de } \\
\text { plágio }\end{array}$} & \multicolumn{4}{|c|}{ NÍVEL DE PLÁGIO } \\
\hline & & & 1 & 2 & 3 & 4 \\
\hline Nenhuma ação & $\begin{array}{c}10.850 \\
(66,2 \%)\end{array}$ & $\begin{array}{c}1.345 \\
(12,4 \%)\end{array}$ & $\begin{array}{c}41 \\
(3,0 \%)\end{array}$ & $\begin{array}{c}192 \\
(14,3 \%)\end{array}$ & $\begin{array}{c}441 \\
(32,8 \%)\end{array}$ & $\begin{array}{c}671 \\
(49,9 \%)\end{array}$ \\
\hline Uma ação & $\begin{array}{c}5.250 \\
(32,0 \%)\end{array}$ & $\begin{array}{c}571 \\
(10,9 \%)\end{array}$ & $\begin{array}{c}23 \\
(4,0 \%)\end{array}$ & $\begin{array}{c}76 \\
(13,3 \%)\end{array}$ & $\begin{array}{c}266 \\
(46,6 \%)\end{array}$ & $\begin{array}{c}206 \\
(36,1 \%)\end{array}$ \\
\hline Duas ações & $\begin{array}{c}300 \\
(1,8 \%)\end{array}$ & $\begin{array}{c}26 \\
(8,7 \%)\end{array}$ & $\begin{array}{c}2 \\
(7,7 \%)\end{array}$ & $\begin{array}{c}7 \\
(26,9 \%)\end{array}$ & $\begin{array}{c}0 \\
(0,0 \%)\end{array}$ & $\begin{array}{c}17 \\
(65,7 \%)\end{array}$ \\
\hline \multicolumn{7}{|c|}{$\begin{array}{l}\text { Legenda: } \\
1 \text { - Coincidência textual mínima; } 2 \text { - Baixa coincidência textual; } \\
3 \text { - Coincidência textual moderada; } 4 \text { - Coincidência textual elevada. }\end{array}$} \\
\hline
\end{tabular}

O Quadro 6 apresenta a quantidade de IES que possuem medidas diagnósticas para combater o plágio, sendo, essencialmente, realizada por meio do uso de software para detecção de plágio.

Quadro 6 - Medidas diagnósticas promovidas nas IES

\begin{tabular}{|l|l|}
\hline \multicolumn{1}{|c|}{ Possui medidas } & \multicolumn{1}{|c|}{ Instituições } \\
\hline \multirow{3}{*}{ Sim } & 8 IES - 17,8\% \\
& $($ IES 9, IES 18, IES 24, IES 26, IES 28, IES 32, IES 39, IES 43) \\
\hline \multirow{5}{*}{ Não } & 37 IES - 82,2\% \\
& $($ IES 1, IES 2, IES 3, IES 4, IES 5, IES 6, IES 7, IES 8, IES 10, IES 11, IES 12, \\
& IES 13, IES 14, IES 15, IES 16, IES 17, IES 19, IES 20, IES 21, IES 22, IES 23, \\
& IES 25, IES 27, IES 29, IES 30, IES 31, IES 33, IES 34, IES 35, IES 36, IES 37, \\
& IES 38, IES 40, IES 41, IES 42, IES 44, IES 45) \\
\hline
\end{tabular}

Fonte: Autoria própria (2017) 
A Tabela 4 apresenta a proporção de plágio produzida nas IES, para os casos das instituições que contam com o suporte de medidas diagnósticas para enfrentar o plágio. Na maior parte dos trechos analisados $(71,3 \%)$, as IES não possuem tais medidas implementadas. A porcentagem calculada na coluna 2 foi efetuada com base no total de trechos analisados (considerando o total de documentos), enquanto que a porcentagem da coluna 3 se baseou no total de trechos analisados por IES/ação.

Tabela 4 - Medidas diagnósticas e o volume de plágio produzido

\begin{tabular}{|c|c|c|c|c|c|c|}
\hline \multirow{2}{*}{$\begin{array}{c}\text { Medidas } \\
\text { diagnósticas }\end{array}$} & \multirow{2}{*}{$\begin{array}{c}\text { Trechos } \\
\text { Analisados }\end{array}$} & \multirow{2}{*}{$\begin{array}{l}\text { Total de } \\
\text { plágio }\end{array}$} & \multicolumn{4}{|c|}{ NÍVEL DE PLÁGIO } \\
\hline & & & 1 & 2 & 3 & 4 \\
\hline Sim & $\begin{array}{c}4.700 \\
(28,7 \%)\end{array}$ & $\begin{array}{c}544 \\
(11,6 \%)\end{array}$ & $\begin{array}{c}21 \\
(3,9 \%)\end{array}$ & $\begin{array}{c}73 \\
(13,3 \%)\end{array}$ & $\begin{array}{c}151 \\
(27,8 \%)\end{array}$ & $\begin{array}{c}299 \\
(55,0 \%)\end{array}$ \\
\hline Não & $\begin{array}{c}11.700 \\
(71,3 \%)\end{array}$ & $\begin{array}{c}1.398 \\
(11,9 \%)\end{array}$ & $\begin{array}{c}45 \\
(3,2 \%)\end{array}$ & $\begin{array}{c}202 \\
(14,4 \%)\end{array}$ & $\begin{array}{c}556 \\
(39,8 \%)\end{array}$ & $\begin{array}{c}595 \\
(42,6 \%)\end{array}$ \\
\hline \multicolumn{7}{|c|}{$\begin{array}{l}\text { Legenda: } \\
1 \text { - Coincidência textual mínima; } 2 \text { - Baixa coincidência textual; } \\
3 \text { - Coincidência textual moderada; } 4 \text { - Coincidência textual elevada. }\end{array}$} \\
\hline
\end{tabular}

Quadro 7 ilustra a quantidade de medidas corretivas desenvolvidas nas IES. Para totalizar os dados contidos, neste quadro foram considerados os seguintes fatores: a) Descrição do plágio em regulamentos internos (regulamento com direitos e deveres dos alunos); b) Adoção de medidas punitivas (advertência, suspensão, expulsão).

Quadro 7 - Medidas corretivas promovidas nas IES

\begin{tabular}{|c|c|}
\hline Medidas corretivas & Instituições \\
\hline Nenhuma ação & $\begin{array}{l}27 \text { IES - 60,0\% } \\
\text { (IES 4, IES 6, IES 8, IES 10, IES 12, IES 13, IES 14, IES 15, IES 17, } \\
\text { IES 19, IES 20, IES 22, IES 23, IES 24, IES 25, IES 27, IES 28, IES } \\
29, \text { IES 31, IES 33, IES 34, IES 35, IES 37, IES 41, IES 42, IES 44, } \\
\text { IES 45) }\end{array}$ \\
\hline Uma ação & $\begin{array}{l}6 \text { IES - 13,3\% } \\
\text { (IES 1, IES 3, IES 7, IES 26, IES 30, IES 43) }\end{array}$ \\
\hline Duas ações & $\begin{array}{l}12 \text { IES - 26,7\% } \\
\text { (IES 2, IES 5, IES 9, IES 11, IES 16, IES 18, IES 21, IES 32, IES 36, } \\
\text { IES 38, IES 39, IES 40) }\end{array}$ \\
\hline
\end{tabular}

Fonte: Autoria própria (2017)

A Tabela 5 identifica a proporção de plágio produzida nas IES, conforme a quantidade de medidas corretivas disponíveis. Dos resultados obtidos, as IES que não promovem nenhuma ação apresentaram a maior taxa de trechos com plágio $(12,8 \%)$, enquanto que aquelas que desenvolvem duas ações tiveram 10,4\% 
trechos com problemas de plágio. A porcentagem calculada na coluna 2 foi efetuada com base no total de trechos analisados (considerando o total de documentos), enquanto que a porcentagem da coluna 3 foi baseada no total de trechos analisados por IES/ação.

Tabela 5 - Medidas corretivas e o volume de plágio produzido

\begin{tabular}{|c|c|c|c|c|c|c|}
\hline \multirow{2}{*}{ Medidas corretivas } & \multirow{2}{*}{$\begin{array}{c}\text { Trechos } \\
\text { Analisados }\end{array}$} & \multirow{2}{*}{$\begin{array}{c}\text { Total de } \\
\text { plágio }\end{array}$} & \multicolumn{5}{|c|}{ NíVEL DE PLÁGIO } \\
\cline { 4 - 7 } & & $\mathbf{1}$ & $\mathbf{2}$ & $\mathbf{3}$ & $\mathbf{4}$ \\
\hline Nenhuma ação & 9.250 & 1.182 & 21 & 174 & 458 & 529 \\
& $(56,4 \%)$ & $(12,8 \%)$ & $(1,8 \%)$ & $(14,7 \%)$ & $(38,7 \%)$ & $(44,8 \%)$ \\
\hline Uma ação & 1.400 & 162 & 15 & 16 & 60 & 71 \\
& $(8,5 \%)$ & $(11,6 \%)$ & $(9,3 \%)$ & $(9,9 \%)$ & $(37,0 \%)$ & $(43,8 \%)$ \\
\hline Duas ações & 5.750 & 598 & 30 & 85 & 189 & 294 \\
$(35,1 \%)$ & $(10,4 \%)$ & $(5,0 \%)$ & $(14,2 \%)$ & $(31,6 \%)$ & $(49,2 \%)$ \\
\hline Legenda: & 1 - Coincidência textual mínima; 2 - Baixa coincidência textual; \\
3 - Coincidência textual moderada; 4 - Coincidência textual elevada. \\
\hline Fonte: Autoria própria (2017)
\end{tabular}

\section{DISCUSSÃO}

Conforme abordado na literatura (ELLIOT; MARQUIS; NEAL, 2013; GOMES, 2014) e recomendado pela Capes, as IES devem desenvolver ações e formalizar políticas institucionais para o combate ao plágio acadêmico. Com efeito, esperase que os trabalhos produzidos nessas instituições não apresentem ilicitudes. Entretanto, não foi possível demonstrar estatisticamente a efetividade das ações, em virtude do volume de plágio registrado, uma vez que a proporção calculada para as IES que não promovem ações $(14,3 \%)$ é inferior às IES que implementam cinco ou mais medidas $(14,7 \%)$.

Outro dado que deve ser considerado é a gravidade do plágio. Os trabalhos com maior percentual de plágios classificados como elevados $(61,7 \%)$ foram encontrados justamente nas instituições com maior número de ações. O resultado é inesperado. Isto pode ter ocorrido em virtude da pequena (ou ineficiente) divulgação das ações à comunidade. Portanto, não se pode afirmar que a existência de maior quantidade de ações promovidas nas IES, produzirá uma menor proporção de trabalhos com problemas. Em alguns casos, estas surtiram pouco efeito no combate ao plágio (IES com apenas uma ação apresentaram os melhores resultados $-11,1 \%$ de trechos com plágio - do que aquelas que implementam duas ou cinco ações - $12,2 \%$ e $14,7 \%$, respectivamente).

Assim, conforme apresentado no Gráfico 1, a hipótese básica (HB) não se confirmou, pois o que se esperava é que, à medida que fossem implantadas ações efetivas, haveria decréscimo no percentual de plágio encontrado. 
Gráfico 1 - Comparação da proporção de plágio e quantidade de ações promovidas

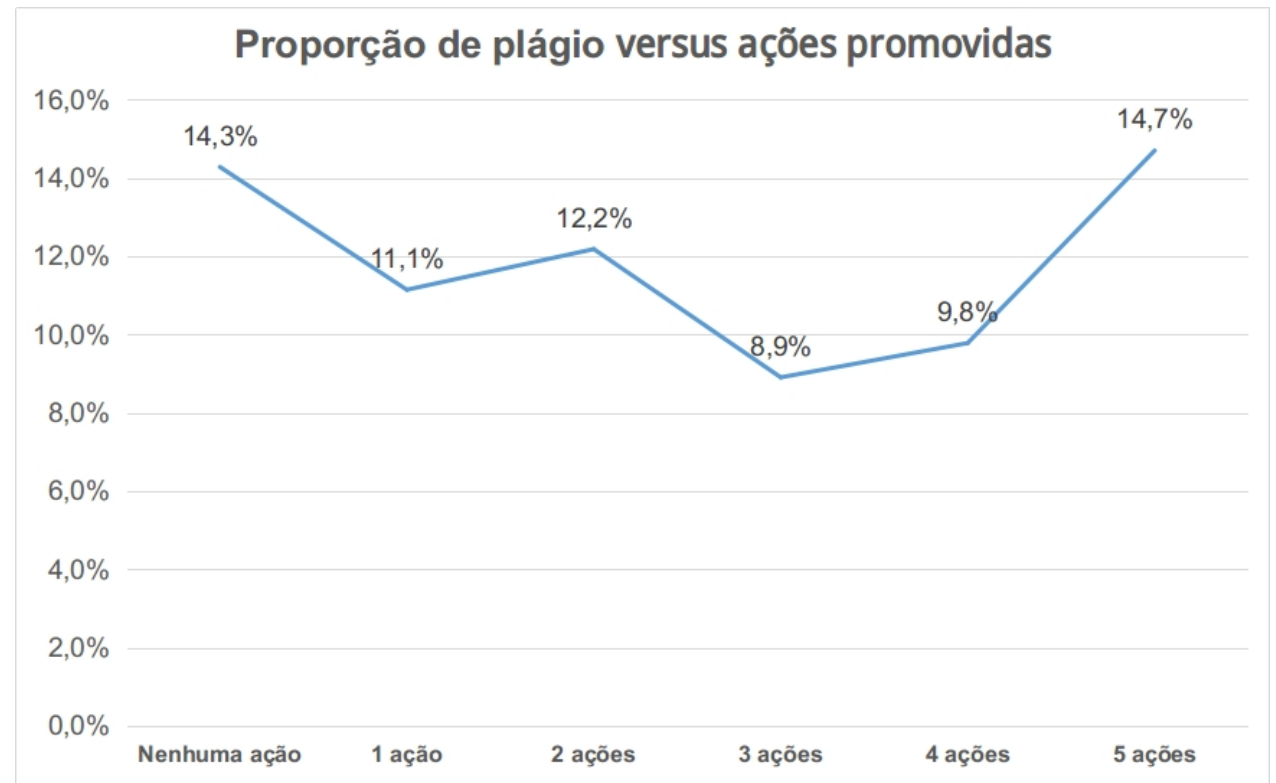

Fonte: Autoria própria (2017)

Ao analisar apenas as ações regulamentares formalizadas (disponibilidade de documentos oficiais que abordem sobre plágio ou nomeação de comissões de integridade científica, por exemplo), verifica-se que o volume de trechos plagiados reduziu ao se incrementar a quantidade de ações (IES com três ações, tiveram a menor proporção de trechos com plágio - 1,4\%), endossando a tese de que estas medidas favorecem o controle/combate ao plágio. Com isso, as ações regulamentares adotadas se mostraram efetivas, confirmando a hipótese HS1.

Analisando as ações preventivas adotadas nas IES, pode-se afirmar que os melhores resultados (menos trechos com plágio) foram obtidos naquelas instituições que desenvolvem as duas medidas em conjunto $(8,7 \%$ de trechos com problema), destacando que a realização de ações preventivas (palestras/capacitação, por exemplo) é fundamental para obter resultados significativos. Isto vem de encontro com o abordado na literatura (BERLINCK, 2011; CAPES, 2011; EVERING; MOORAN, 2012; SARLAUSKIENE; STABINGIS, 2014), no qual ressalta que as ações para capacitação da comunidade são fundamentais no combate ao plágio. Os dados obtidos mostram que as ações preventivas adotadas se mostraram efetivas, confirmando a hipótese HS2.

Em se tratando de medidas diagnósticas desenvolvidas nas IES analisadas, pode-se concluir que a utilização de um software como suporte à detecção do plágio em trabalhos acadêmicos mostrou-se pouco eficiente, uma vez que as IES que adotam alguma ferramenta apresentaram praticamente o mesmo percentual de trechos plagiados daquelas IES que não contam com o suporte de software algum (11,6\% e $11,9 \%$, respectivamente). Isto reforça o argumento apresentado na literatura (BERLINCK, 2011; DEGEETER et al., 2014) de que usar um software nem sempre é a melhor estratégia para combater o plágio. Assim, apesar de 
terem sido encontrados trechos com plágio as IES que têm um software para detecção, uma pequena melhora pode ser notada ao usar uma ferramenta. Com isso, a hipótese HS3 se confirmou parcialmente.

Por fim, ao avaliar as medidas corretivas institucionalizadas, quanto maior o número de ações desta categoria, verifica-se uma pequena redução no volume de trechos plagiados (nenhuma ação $=12,8 \%$; duas ações $=10,4 \%$ ). Assim, podese entender que tais medidas foram pouco efetivas. Os dados ilustram que as 12 IES que implementam as duas ações obtiveram, apesar de pouca diferença, resultados melhores do que as categorias anteriores. Isto reforça o enfatizado na literatura, relativo à importância em regulamentar, nos regimentos internos, as punições para os casos de desonestidade acadêmica (WACHOWICZ; COSTA, 2016; SANTOS, 2017). Com isso, a hipótese HS4 se confirmou parcialmente.

\section{CONCLUSÃO}

Esta pesquisa teve por objetivo efetuar o comparativo entre as medidas de combate ao plágio, implementadas pelas IES e o volume de plágio encontrado em teses e dissertações defendidas. Para analisar os resultados obtidos comparando o índice de plágio nos documentos e a eficácia das medidas disponíveis nas IES, estas foram distribuídas em quatro categorias: ações regulamentares (quatro ações, p.e. políticas estabelecidas), ações preventivas (duas ações, p.e. ações de capacitação), medidas diagnósticas (uma ação, p.e. software de detecção de plágio) e medidas corretivas (duas ações, p.e. regulamento disciplinar).

Analisando isoladamente as medidas desenvolvidas, segundo as quatro categorias definidas no estudo, foi possível verificar que, apesar de algumas IES que implementam ações regulamentares (até quatro ações) e ações preventivas (até duas medidas) terem apresentado menos trechos com problema, os resultados são insuficientes para garantir o combate sistemático ao plágio, uma vez que grande parte dos documentos analisados destas IES tiveram um volume significativo de trechos plagiados de outros autores.

Em se tratando de plágio, o cenário ideal é inexistir trechos com este problema, independentemente do tipo do trabalho acadêmico apresentado. Entretanto, registra-se o elevado índice de plágio encontrado nos documentos analisados $(11,8 \%$ de trechos com problema, sendo $82,4 \%$ destes classificados nas categorias coincidência textual moderada e elevada). Cabe registrar a preocupação limitada das instituições, uma vez que a maioria delas (27 IES $60,0 \%)$ promove, no máximo, duas ações (de nove analisadas).

Assim, com base nos resultados obtidos nesta pesquisa, fica evidente a ineficácia das medidas de combate ao plágio, promovidas pelas IES (nove ações ao todo). Foi possível notar, também, que aumentar o número de medidas realizadas (até o limite de nove ações) ou não implementar nenhuma ação, não produziu diferença significativa de enfrentamento, uma vez que os resultados obtidos ficaram muito próximos $(14,3 \%$ de trechos com plágio para IES que não possuem ações desenvolvidas contra $14,7 \%$ de trechos encontrados nos documentos de IES com cinco ações implementadas).

Com isso, se faz necessário desenvolver, aprimorar e/ou intensificar as medidas de combate ao plágio disponíveis em cada IES que oferta algum programa de pós-graduação na área de Ensino. Tais medidas proporcionarão à 
comunidade a devida compreensão de que tal atitude fere os direitos autorais, que se conscientizem em evitar o plágio no desenvolvimento dos trabalhos e, que as IES punam severamente os responsáveis e que seja possível antecipar os problemas existentes no documento antes de sua divulgação. 


\title{
Measures to combat plagiarism adopted by higher education institutions: an analysis of the effectiveness actions in the area of Education
}

\begin{abstract}
The objective of the present study is to examine if actions to combat plagiarism in Higher Education Institutions (HEI) result in lower plagiarism problems index in published dissertations and theses. This bibliographical research was carried out in Education postgraduate (Master's degree, Master's professional degree and Doctoral degree) programs in Brazil. The documentary corpus was composed by 330 dissertations and theses, selected from 45 programs, submitted from 2010 to 2012 and available through the Google search engine. 50 excerpts from each document (from the sections: introduction -5 , theoretical reference - 30 , methodology - 5 , results and discussion - 10) were analyzed. Data were analyzed through descriptive statistics. Analyzing an isolating the implemented measures, it is noticed that the regulatory actions (policies and regulations) and preventive actions (community orientation), although they presented smaller indexes of parts with plagiarism, were ineffective. It is concluded that the measures to combat plagiarism promoted by HEI are ineffective, since many parts with problems have been found, even in those HEls in which some practice is formalized, and it is necessary to intensify or improve the actions to confront and eliminate this problem.
\end{abstract}

KEYWORDS: Plagiarism. Postgraduate. Teaching. Institutional Actions. 


\section{REFERÊNCIAS}

ALENCAR, L. B. D. Práticas de orientação de TCC em curso de graduação em Ciências Contábeis em IES da cidade de São Paulo que possuem Stricto Sensu. 2016. 209 f. Dissertação (Mestre em Ciências Contábeis). Fundação Escola de Comércio Álvares Penteado - FECAP, São Paulo - SP.

ANDERSON, M. S.; STENECK, N. H. The problem of plagiarism. Urologic Oncology: Seminars and Original Investigations, v. 29, n. 1, feb. 2011. Disponível em: <https://goo.gl/Dph2Ju>. Acesso em: 24 jan. 2017.

BERLINCK, R. G. S. The academic plagiarism and its punishments - a review. Revista Brasileira de Farmacognosia, v. 21, n. 3, jun. 2011. Disponível em: <https://goo.gl/cJrHvS >. Acesso em: 24 jan. 2017.

BRASIL. Lei no 9.610, de 19 de Fevereiro 1998. Altera, atualiza e consolida a legislação sobre direitos autorais e dá outras providências. Brasília, DF, 19 fev. 1998. Disponível em: <https://goo.gl/wyKFjp>. Acesso em: 12 ago. 2017.

CAPES. Orientações Capes - Combate ao plágio. 2011. Disponível em <https://goo.gl/ZOKCXG>. Acesso em: 06 mai. 2014.

CHIARINI, T.; VIEIRA, K. P. Universidades como produtoras de conhecimento para o desenvolvimento econômico: sistema superior de ensino e as políticas de CT\&I. Revista Brasileira de Economia, v. 66, n. 1, jan. 2012. Disponível em: $<$ https://goo.gl/X3kjFv>. Acesso em: 24 jan. 2017.

COURY, H. J. C. G. Integridade na pesquisa e publicação científica. Revista Brasileira de Fisioterapia, v. 16, n. 1, fev. 2012. Disponível em: <https://goo.gl/2rP6UG >. Acesso em: 24 jan. 2017.

DALLA COSTA, R. M .C. Plágio acadêmico: a responsabilidade das associações científicas. Intercom - Revista Brasileira de Ciências da Comunicação, v. 39, n. 3, dez. 2016. Disponível em: <https://goo.gl/Jq63U5>. Acesso em 24 jan. 2017.

DEGEETER, M.; HARRIS, K.; KEHR; H; FORD, C.; LANE, D. C.; NUZUM, D. S.; COMPTON, C.; GIBSON, W. Pharmacy students ability to identify plagiarism after an educational intervention. American Journal of Pharmaceutical Education, $v$. 78, n. 2, 2014. Disponível em: <https://goo.gl/vNdwr4>. Acesso em: 24 jan. 2017. 
ELLIOTT, T. L.; MARQUIS, L. M.; NEAL, C. S. Business ethics perspectives: faculty plagiarism and fraud. Journal of Business Ethics, v. 112, n. 1, feb. 2013.Disponível em: $\langle$ https://goo.gl/yFd17s $>$. Acesso em: 24 jan. 2017.

ESTEVES, B. Punição tardia. O Estado de São Paulo. São Paulo, fev. 2014. Disponível em: <https://goo.gl/pYBvxg>. Acesso em: 01 de ago. 2017.

EVERING, L. C.; MOORMAN, G. Rethinking plagiarism in the digital age. Journal of Adolescent \& Adult Literacy, v. 56, n. 1, sep. 2012.Disponível em: <https://goo.gl/6EHX2d >. Acesso em: 24 jan. 2017.

FANELLI, D. How many scientists fabricate and falsify research? A systematic review and meta-analysis of survey data. PloS One, v. 4, n. 5, may. 2009. Disponível em: <https://goo.gl/AgU9HJ>. Acesso em: 24 jan. 2017.

GOMES, S. L. R. O Acesso Aberto ao conhecimento científico: o papel da universidade brasileira. Revista Eletrônica de Comunicação, Informação \& Inovação em Saúde, v. 8, n. 2, 2014. Disponível em: <https://goo.gl/47SR98>. Acesso em: 24 jan. 2017.

HOLT, E. A. Education improves plagiarism detection by biology undergraduates. Bioscience, v. 62, n. 6, jun. 2012. Disponível em: <https://goo.gl/3GDY8B >. Acesso em: 24 jan. 2017.

INNARELLI, P. B. Fatores antecedentes na atitude de alunos de graduação frente ao plágio. 2011. 84 f. Dissertação (Mestrado em Administração) Universidade Metodista de São Paulo - UMESP, São Bernardo do Campo - SP.

JORDAN, S. R., GRAY, P. W. Research Integrity in Greater China: Surveying regulations, perceptions and knowledge of research integrity from a Hong Kong perspective. Developing world bioethics, v. 13, n. 3, dec. 2012. Disponível em <https://goo.gl/efykr1>. Acesso em 24 jan. 2017.

KROKOSCZ, M. Abordagem do plágio nas três melhores universidades de cada um dos cinco continentes e do Brasil. Revista Brasileira de Educação, v. 16, n. 48, set. 2011.Disponível em: <https://goo.gl/bKL6MB>. Acesso em: 24 jan. 2017.

LIU, G.; LO, H.; WANG, H. Design and usability testing of a learning and plagiarism avoidance tutorial system for paraphrasing and citing in english: a case study. Computers \& Education, v. 69, nov. 2013. Disponível em: <https://goo.gl/b12Q8h>. Acesso em: 24 jan. 2017. 
MARSHALL, T., TAYLOR, B., HOTHERSALL, E., PÉREZ-MARTíN, L. Plagiarism: a case study of quality improvement in a taught postgraduate programme. Medical Teacher, v. 33, n. 7, jun. 2011. Disponível em: <https://goo.gl/b2YyRf >. Acesso em: 24 jan. 2017.

MARTIN, B. R. Whither research integrity? Plagiarism, self-plagiarism and coercive citation in an age of research assessment. Research Policy, v. 42, n. 5, apr. 2013. Disponível em: <https://goo.gl/SLSf3r>. Acesso em: 24 jan. 2017.

MORAES, R. Plágio na pesquisa acadêmica: a proliferação da desonestidade intelectual. Diálogos Possíveis, v. 3, n. 1, 2014. Disponível em: <https://goo.gl/NwCk64>. Acesso em: 11 ago. 2017.

OAB. Combate ao Plágio - Comissão Nacional de Relações Institucionais do Conselho Federal da OAB. 2010. Disponível em:<https://goo.gl/xJW4ld $>$.Acesso em: 06 abr. 2014.

PREVEDELLO, C. F.; ROSSI, W. S.; COSTA, A. C. R. Direito Autoral na Produção de Materiais Didáticos para a Educação a Distância: reflexões para a utilização na era da informação. Revista Thema, v. 12, n. 2, 2015. Disponível em: <https://goo.gl/2vkVx1>. Acesso em 12 ago. 2017

SANTOS, F. C. A concepção de trabalho acadêmico de alunas de um curso de pedagogia a distância: um estudo de caso. 2015. 115 f. Dissertação (Mestrado em Linguística Aplicada). Universidade do Vale do Rio dos Sinos - UNISINOS, São Leopoldo - RS.

SARLAUSKIENE, L.; STABINGIS, L. Understanding of Plagiarism by the Students in HEls of Lithuania. Procedia-Social and Behavioral Sciences, v. 110, n. 1, jan. 2014. Disponível em: <https://goo.gl/Ogej5K>. Acesso em: 24 jan. 2017.

SILVA, O. S. F. Entre o plágio e a autoria: qual o papel da universidade. Revista Brasileira de Educação, v. 13, n. 38, mai. 2008. Disponível em: <https://goo.gl/L8VPsZ>. Acesso em: 24 jan. 2017.

TANIGUCHI, S. P. Desonestidade acadêmica: interação entre fatores pessoais e práticas de grupo na atitude de estudantes de IES. 2011. 64 f.. Dissertação (Mestrado em Administração). Universidade Metodista de São Paulo - UMESP, São Bernardo do Campo - SP.

THOMAS, J. R.; NELSON, J. K.; SILVERMAN, S. J. Métodos de pesquisa em 
VASCONCELOS, S.; LETA, J.; COSTA, L.; PINTO, A.; SORENSON, M. M. Discussing plagiarism in latin american science. EMBO Reports, v. 10, n. 7, june 2009. Disponível em: <https://goo.gl/zfZSMe>. Acesso em: 24 jan. 2017.

VELUDO-DE-OLIVEIRA, T. M., AGUIAR, F. H., QUEIROZ, J. P., BARRICHELLO, A. Cola, plágio e outras práticas acadêmicas desonestas: um estudo quantitativodescritivo sobre o comportamento de alunos de graduação e pós-graduação da área de negócios. Revista de Administração Mackenzie, v. 15, n. 1, mar. 2013. Disponível em: <https://goo.gl/CbF93m>. Acesso em 24 jan. 2017.

WACHOWICZ, M. Direito autoral, recursos educacionais e licenciamentos criativos: acesso à cultura, ao conhecimento e à educação. Em Aberto, v. 28, n. 94, 2015. Disponível em: <https://goo.gl/Z6uBBZ>. Acesso em 14 ago. 2017.

WACHOWICZ, M., COSTA, J. A. F. Plágio acadêmico. Curitiba: Gedai Publicações/UFPR, 2016.

WATANABE, E. H. A não linearidade entre a reação de quem copia e de quem é copiado. Estudos Avançados, v. 28, n. 80, abr. 2014. Disponível em: <https://goo.gl/VlHlym>. Acesso em: 24 jan. 2017.

YOUMANS, R. J. Does the adoption of plagiarism-detection software in higher education reduce plagiarism? Studies in Higher Education, v. 36, n. 7, may. 2011. Disponível em: <https://goo.gl/T6ubyb>. Acesso em: 24 jan. 2017.7

Recebido: 2018-02-09

Aprovado: 2018-02-09

DOI: $10.3895 /$ rbect.v10n3.7745

Como citar:

AIRES, J. P.: PILATTI, L. A. Medidas de combate ao plágio, adotadas por instituições de ensino superior: uma análise da efetividade das ações na área de Ensino. Revista Brasileira de Ensino de Ciência e Tecnologia, v.

10, n. 3, 2017. Disponível em: <https://revistas.utfpr.edu.br/rbect/article/view/ 7745>. Acesso em: xxx. Correspondência:

João Paulo Aires - joao@utfpr.edu.br.

Direito autoral: Este artigo está licenciado sob os termos da Licença Creative Commons-Atribuição 4.0 Internacional. 